\title{
Combined Effect of Sodium Sulphate and Superplasticizer on the Hydration of Fly Ash Blended Portland ${ }^{\circledR}$ Cement
}

\author{
Mukesh Kumar ${ }^{\mathrm{a}}$, Narendra Pratap Singh ${ }^{\mathrm{b}}$, Sanjay Kumar Singh ${ }^{\mathrm{c}}$, Nakshatra Bahadur Singh ${ }^{\mathrm{d}, *}$ \\ ${ }^{a}$ Kryton, Buildmat Company, Pvt. Ltd., Gurgaon, 122102, India \\ ${ }^{\mathrm{b}}$ Department of Chemistry, U. P. Autonomous College, Varanasi, 221002, India \\ 'Institute of Engineering and Technology, Lucknow, 226021, India \\ ${ }^{\mathrm{d}} R T D C$, School of Engineering, Sharda,University, Greater Noida, India
}

Received: November 7, 2009; Revised: March 19, 2010

\begin{abstract}
Combined effect of polycarboxylate type superplasticizer and sodium sulphate on the hydration of fly ash blended Portland ${ }^{\circledR}$ cement has been studied by using different techniques. Water consistency, setting times, non-evaporable water contents, water percolation, air contents, compressive strengths and expansion in corrosive atmosphere were determined. Hydration products were examined with the help of DTA and X-ray diffraction techniques. It is found that the superplasticizer reduces the pore size and its adsorption on cement surfaces is decreased in the presence of sodium sulphate. Mechanism of hydration is discussed.
\end{abstract}

Keywords: Portland ${ }^{\circledR}$ cement, fly ash, superplasticizer, sodium sulphate, hydration

\section{Introduction}

There is a continuous decrease of natural resources on one hand and rapid increase of industrial and agricultural wastes on the other hand, which create handling, disposal and environmental problems. The pozzolanic activities of these materials prompted a partial replacement of clinker in cement to make composite cements ${ }^{1,2}$. Cementitious binders are vital for all types of construction activities. The uses of composite cements as alternatives to Portland ${ }^{\circledR}$ cement have been introduced in the last few decades either for cost reduction, performance, durability or environmental reasons.

Now-a-days, fly ash and other ashes from agricultural wastes are commonly used for partial replacement of cement clinker. The composite cements are also used for the development of ultrahigh performance concretes. This is mainly based on the drastic reduction of the water-cement ratio with superplasticizer additions to maintain a good workability, and the improvement of aggregate size and close packing with reactive filler (pozzolana e.g. fly ash). The major disadvantage of fly ash additions is low early strengths of the concrete ${ }^{3}$. Various methods both mechanical and chemical have been used to activate fly ash to overcome this problem ${ }^{4,5}$. However satisfactory results have not been obtained so far.

In this paper we have studied the effect of sodium sulphate on the hydration of fly ash composite cement in the presence of a polycarboxylate type superplasticizer with a brand name Glenium 51.

\section{Experimental}

\subsection{Materials}

Portland ${ }^{\circledR}$ cement (OPC) obtained from Vikram Cement, India was used for hydration studies. The Oxide and mineralogical compositions are given in Tables 1 and 2 respectively. Particle size distribution of Portland $^{\circledR}$ cement is given in Figure 1. Fly Ash (FA) was obtained from Dadri Thermal Power Plant. The chemical composition of fly ash is given in Table 3. Its Blain surface area is about $3200 \mathrm{~cm}^{2} \cdot \mathrm{g}^{-1}$.
Glenium 51 ( BASF chemicals construction company India), a light brown coloured liquid with a specific gravity of 1.08 at $25^{\circ} \mathrm{C}$, chloride content $<0.2$ wt. (\%) and $\mathrm{pH}>6$ was used as a polycarboxylate type superplasticizer (SP). Sodium Sulphate $\left(\mathrm{Na}_{2} \mathrm{SO}_{4}\right)$ (Merck) was used as an accelerating admixture. $20 \mathrm{wt}$. (\%) fly ash OPC composite cement (FAOPC) was used for hydration.

\subsection{Methods}

\subsubsection{Determination of standard water consistency}

The water consistencies were determined with the help of Vicat apparatus (I S: 4031 part 4, 1988).

\subsubsection{Determination of setting times}

Initial and final setting times were determined with the help of Vicat apparatus (I S: 4031 part 5, 1988).

\subsubsection{Preparation of hydrated samples}

Ten grams of OPC and FAOPC in the absence and presence of 0.1 wt. (\%) SP, 2.0 wt. (\%) $\mathrm{Na}_{2} \mathrm{SO}_{4}$ and their combination were thoroughly mixed separately in polythene bags with $3 \mathrm{ml}$ water so that $\mathrm{w} / \mathrm{c}$ ratio became 0.3 . The air inside the bags was removed in order to avoid carbonations. The hydration reactions were allowed to continue at room temperature $\left(\approx 28{ }^{\circ} \mathrm{C}\right)$ and stopped at different intervals of time (1, 3,7,14 and 28 days) with isopropyl alcohol and diethyl ether. The hydrated samples were heated at $105{ }^{\circ} \mathrm{C}$ for 1 hour. The dried samples were stored in polythene bags and kept in a desiccator.

\subsubsection{Determination of non-evaporable water contents}

Approximately one gram samples hydrated for different time intervals were weighed in ceramic crucibles and heated at $105{ }^{\circ} \mathrm{C}$ for 1 hour in order to remove adsorbed water. When removed from the oven, the mass of the crucibles and samples were determined 
Table 1. Oxide composition of Portland cement.

\begin{tabular}{cccccccccccccc}
\hline Oxide & $\mathrm{SiO}_{2}$ & $\mathrm{Al}_{2} \mathrm{O}_{3}$ & $\mathrm{Fe}_{2} \mathrm{O}_{3}$ & $\mathrm{CaO}$ & $\mathrm{MgO}$ & $\mathrm{K}_{2} \mathrm{O}$ & $\mathrm{Na}_{2} \mathrm{O}$ & $\mathrm{TiO}_{2}$ & $\mathrm{PbO}$ & $\mathrm{ZnO}_{2}$ & $\mathrm{MnO}_{2}$ & $\mathrm{P}_{2} \mathrm{O}_{5}$ & $\mathrm{SO}_{3}$ \\
\hline Composition wt. (\%) & 19.5 & 4.84 & 3.26 & 62.66 & 4.19 & 0.54 & 0.06 & 0.44 & 0.77 & 0.09 & 0.15 & 0.03 & 2.13 \\
\hline
\end{tabular}

Table 2. Mineralogical composition of Portland cement.

\begin{tabular}{ccccc}
\hline Phase & $\mathrm{C}_{3} \mathrm{~S}$ & $\mathrm{C}_{2} \mathrm{~S}$ & $\mathrm{C}_{3} \mathrm{~A}$ & $\mathrm{C}_{4} \mathrm{AF}$ \\
\hline Composition wt. (\%) & 76.8 & 5.51 & 7.31 & 9.92
\end{tabular}

Table 3. Chemicalcompositionof Fly Ash.

\begin{tabular}{lc}
\hline Constituents & Composition wt. (\%) \\
\hline Silicon dioxide & 59.02 \\
Aluminum oxide & 38.02 \\
Magnesium oxide & 0.28 \\
Sodium oxide & 0.47 \\
Potassium oxide & 0.22 \\
Calcium oxide & 0.94 \\
Loss on ignition & 1.05 \\
\hline
\end{tabular}

again before placing them in a furnace at $1000{ }^{\circ} \mathrm{C}$ for a minimum of 1 hour. From mass losses at $1000{ }^{\circ} \mathrm{C}$ the non-evaporable water contents were calculated.

\subsubsection{Determination of water percolation by permeability} apparatus

Following mixtures:

$140 \mathrm{~g} \mathrm{OPC}+28 \mathrm{~g} \mathrm{FA}+700 \mathrm{~g}$ sand

$140 \mathrm{~g} \mathrm{OPC}+28 \mathrm{~g} \mathrm{FA}+700 \mathrm{~g}$ sand $+0.14 \mathrm{~g} \mathrm{SP}$;

$140 \mathrm{~g} \mathrm{OPC}+28 \mathrm{~g} \mathrm{FA}+700 \mathrm{~g}$ sand $+2.8 \mathrm{~g} \mathrm{Na}_{2} \mathrm{SO}_{4}$; and

$140 \mathrm{~g} \mathrm{OPC}+28 \mathrm{~g} \mathrm{FA}+700 \mathrm{~g}$ sand $+2.8 \mathrm{~g} \mathrm{Na}_{2} \mathrm{SO}_{4}+0.14 \mathrm{SP}$

Were mixed separately with $42 \mathrm{ml}$ water in order to have water/solid (w/s) ratio of 0.3 . The mortars were thoroughly mixed in Hobart mixer. Each mortar was placed in a mould as per IS 2645. After 24 hours, the mortars were demoulded and immersed in water tanks separately for 20 days. The moulds were then fixed in a permeability apparatus where pressure of $2.0 \mathrm{~kg} . \mathrm{cm}^{-2}$ was applied (pressure was slowly increased from 0.5 to $2.0 \mathrm{~kg} . \mathrm{cm}^{-2}$ ). Water percolation was measured at every 1 hour in terms of weight of percolated water for 8 hours.

\subsubsection{Determination of air contents}

Air contents of the concrete made from the above mixtures were determined with the help of Air Entrainment apparatus.

\subsubsection{Determination of compressive strength}

Compressive strength of cement mortars (OPC: sand-1:3) in the absence and presence of $\mathrm{FA}, \mathrm{Na}_{2} \mathrm{SO}_{4}$ and $\mathrm{SP}$ were determined with the help of compressive strength testing machine at 28 days of hydration.

\subsubsection{Effect of corrosive atmosphere on hydrated cement}

Cylindrical moulds of OPC and FAOPC in the presence and absence of $\mathrm{Na}_{2} \mathrm{SO}_{4}$ and $\mathrm{SP}$ (diameter $3.0 \mathrm{~cm}$ and length $3.0 \mathrm{~cm}$ ) were prepared at a w/c ratio of 0.3 . After 24 hours the cement cylinders were removed from the moulds and kept under water for 28 days for

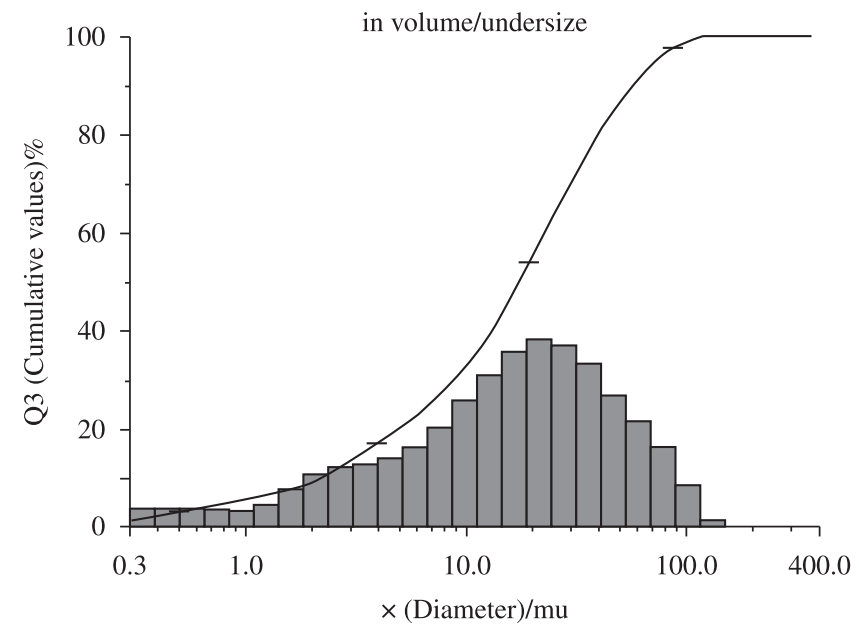

Figure 1. Particle size distribution of Portland ${ }^{\circledast}$ cement.

curing. These moulds were then kept in $\mathrm{N} / 60 \mathrm{H}_{2} \mathrm{SO}_{4}$ and expansions were measured as a function of time with the help of Le Chatelier's apparatus.

\subsection{DTA studies}

DTA studies of hydrated samples were carried out using NETZSCH STA instrument under nitrogen atmosphere at a heating rate of $10^{\circ} \mathrm{C} / \mathrm{min}$.

\subsection{X-ray diffraction studies}

Powder X-ray diffraction patterns were recorded with X-ray diffractograph using $\mathrm{CuK} \alpha$ radiations.

\section{Results and Discussion}

The chemical reaction taking place during hydration of cement is generally more complex than simple conversions of anhydrous compounds into the corresponding hydrates. The hydration reaction is exothermic in nature and as soon as cement comes in contact to water, setting and hardening processes start. For making a paste of standard consistency, certain optimum w/c ratio is required. The change in water consistency for FAOPC in the presence of $\mathrm{SP}, \mathrm{Na}_{2} \mathrm{SO}_{4}$, and their combination are given in Figure 2. The water consistency of FAOPC is higher than that of OPC alone. This may be due to higher surface area of FA. In the presence of $0.1 \mathrm{wt}$. (\%) SP, the water consistency is decreased as normally expected in the presence of a superplasticizer. However 2.0 wt. (\%) $\mathrm{Na}_{2} \mathrm{SO}_{4}$ increased the water consistency. This is due to its accelerating effect during the hydration of cement as well as its role in activating the activity of FA. In the presence of a mixture of $0.1 \mathrm{wt}$. (\%) SP and $2.0 \mathrm{wt}$. (\%) $\mathrm{Na}_{2} \mathrm{SO}_{4}$, the water consistency is decreased but higher than that in the presence of $\mathrm{SP}$ alone. This shows that in the presence of $\mathrm{Na}_{2} \mathrm{SO}_{4}$ the adsorption of SP on the surface of FAOPC particles is decreased and hence the dispersive forces are reduced.

It has been reported that different cements and different cement phases adsorb different quantities of superplasticizers. Additionally, soluble salts like $\mathrm{Na}_{2} \mathrm{SO}_{4}$ and the time of superplasticizer addition 


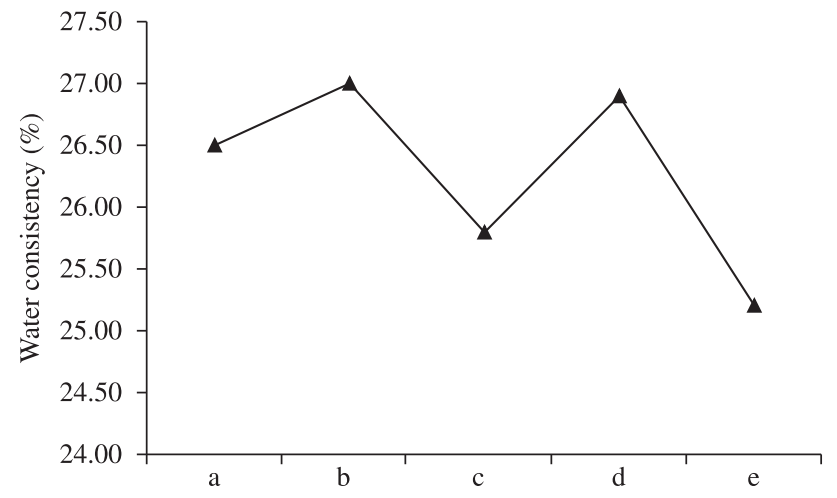
a) $\mathrm{OPC}$
b) $\mathrm{OPC}+20 \%$ fly ash
c) $\mathrm{OPC}+20 \%$ fly ash $+0.1 \% \mathrm{SP}$
d) $\mathrm{OPC}+20 \%$ fly ash $+2 \% \mathrm{Na}_{2} \mathrm{SO}_{4}$
e) $\mathrm{OPC}+20 \%$ fly ash $+2 \% \mathrm{Na}_{2} \mathrm{SO}_{4}+0.1 \% \mathrm{SP}$

Figure 2. Variation of water consistency.

were found to influence the superplasticizer adsorption behavior ${ }^{6,7}$. Up to a certain extent, this can be explained by different zeta potentials of the various cement phases. In the absence of a superplasticizer, zeta potential was found to be positive $(23 \mathrm{mV})$ for $\mathrm{C}_{3} \mathrm{~A}$ and negative $(-9 \mathrm{mV})$ for $\mathrm{C}_{3} \mathrm{~S}^{6}$. In a saturated $\mathrm{CaSO}_{4}$ solution the zeta potentials of $\mathrm{C}_{3} \mathrm{~A}$ and $\mathrm{C}_{3} \mathrm{~S}$ were shifted towards 0 and $-12 \mathrm{mV}$, respectively. By this way, the addition of gypsum impedes a flash set of the cement, since the charge of the two cement phases is not oppositional anymore. If superplasticizers are added, the negatively charged superplasticizer polymers are adsorbed more on $\mathrm{C}_{3} \mathrm{~A}$, since its charge is less negative compared to the one of $\mathrm{C}_{3} \mathrm{~S}$. Therefore, negatively charged superplasticizers have a higher affinity for $\mathrm{C}_{3} \mathrm{~A}$ than for $\mathrm{C}_{3} \mathrm{~S}$. In colloid chemistry an increasing amount of electrolytes (i.e. increased ionic strength) compresses the electric double layer around the particles. Therefore, the fluidity of a suspension should decrease by the fact that particles get closer together. For hydrating cement systems, the situation is more complex, since the electrolytes are able to participate in the hydration reactions. For superplasticized cement systems it was found that the addition of soluble sulphates $\left(\mathrm{K}_{2} \mathrm{SO}_{4}, \mathrm{Na}_{2} \mathrm{SO}_{4}\right.$, hemihydrate) reduced the adsorbed amount of superplasticizer ${ }^{6,8,9}$. This implies that sulphates hinder the adsorption on $\mathrm{C}_{3} \mathrm{~A}$ and therefore less superplasticizer polymers are incorporated into hydrates during the first minutes of cement hydration ${ }^{6}$.

The variation of initial and final setting times is shown in Figure 3. The setting times for FAOPC are lower than that of OPC. It is already reported that in the presence of FA heat evolution is higher than that of OPC alone. Due to larger amount of heat evolved, the hydration is accelerated and hence setting times are reduced. Since SP is a water reducer and during early hours it behaves as retarder, setting times are increased in its presence. $\mathrm{Na}_{2} \mathrm{SO}_{4}$ is a well known accelerator for cement hydration and it also activates the activity of FA. Therefore the hydration reaction is increased in the presence $\mathrm{Na}_{2} \mathrm{SO}_{4}$. As a result the setting times are decreased. In the presence of combination of 0.1 wt. (\%) SP and 2.0 wt. (\%) $\mathrm{Na}_{2} \mathrm{SO}_{4}$, the setting times are slightly higher than that in the presence of $\mathrm{Na}_{2} \mathrm{SO}_{4}$ alone but much lower than that in the presence of SP. This again confirms that in the presence of $\mathrm{Na}_{2} \mathrm{SO}_{4}$, the adsorption of SP on the surface of FAOPC particles is reduced.

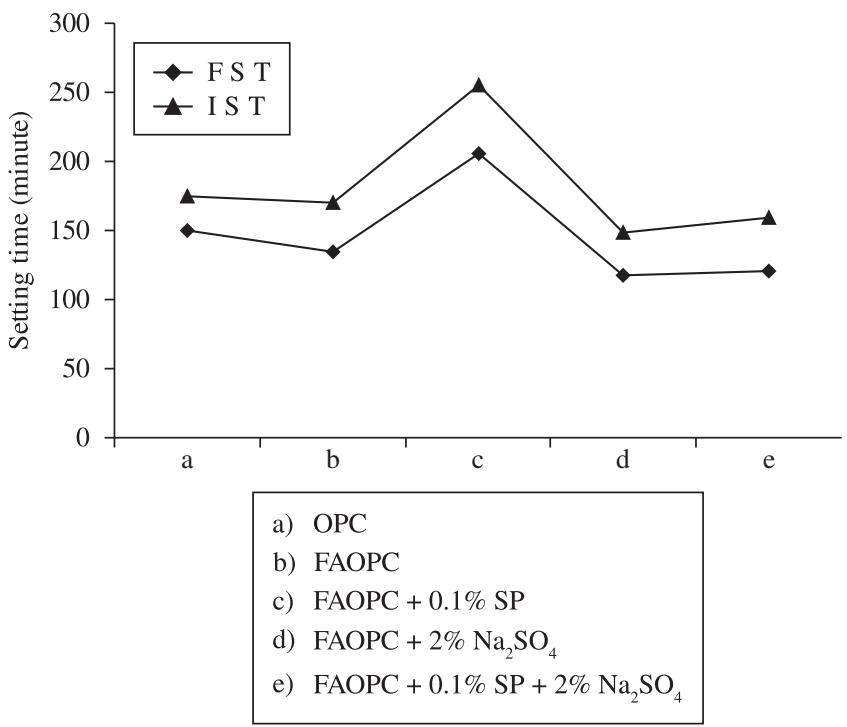

Figure 3. Variation of setting times.

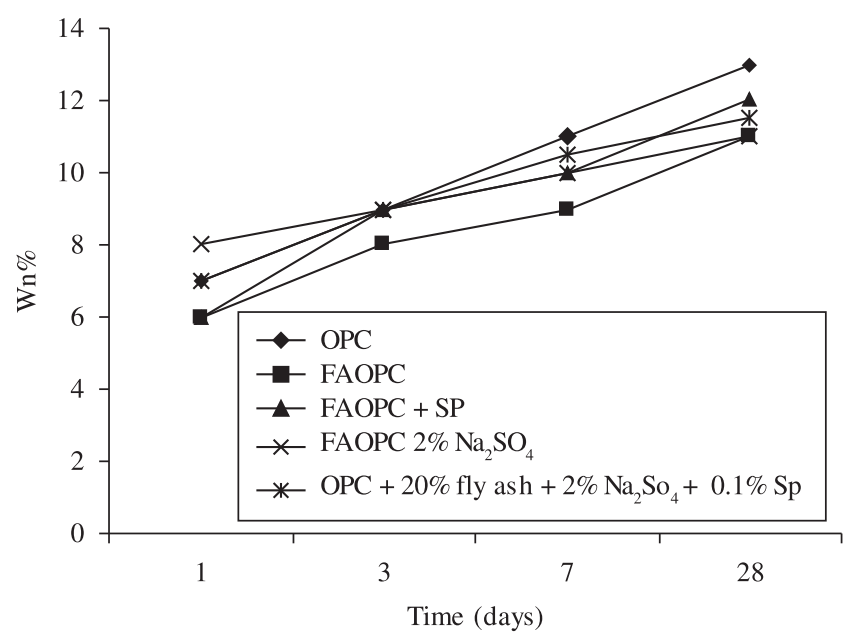

Figure 4. Variation of non - evaporable water content with hydration time.

During hydration water reacts with cement constituents forming hydrated compounds. Two types of water: evaporable and non-evaporable water are present in the hydrated cement. The evaporable water can be determined by heating at $105{ }^{\circ} \mathrm{C}$, or by freezing out or removing with solvent. The non-evaporable water contents $\left(\mathrm{W}_{\mathrm{n}}\right)$ or chemically combined water has a rough estimate of the degree of hydration and can be determined from the weight loss at $1000{ }^{\circ} \mathrm{C}$. The variation of $\mathrm{W}_{\mathrm{n}}$ with hydration time is shown in Figure 4 . The values continuously increase with time in all the cases. This simply indicates that the degree of hydration increases with time but there is no definite sequence.

The different mineral phases within the cement hydrate with different rates forming various reaction products. Some products deposit on the unreacted cement particle surfaces (surface products) while others form as crystals in the water-filled pore space between cement particles (pore products). For simplicity, cement paste can be thought of as consisting of four phases: (i) unreacted cement, (ii) surface products (like $\mathrm{C}-\mathrm{S}-\mathrm{H}$ ), (iii) pore products (like calcium hydroxide), and (iv) capillary pore space. FA reduces $\mathrm{CH}$ and increases $\mathrm{C}-\mathrm{S}-\mathrm{H}$. For the same period of hydration $\mathrm{Na}_{2} \mathrm{SO}_{4}$ accelerates the hydration and will increase the amount of hydration products. Surface products grow outward from the unreacted cement particles and contain connected 
(percolated) gel pores, while pore products are generally polycrystalline and fully dense, with no connected pores. The capillary pores are the water-filled space between solid phases and generally range from about 0.01 to $0.1 \mu \mathrm{m}$ in size, in a reasonably well-hydrated cement paste, although during early hydration, they can range up to a few micrometers in size. These pores are responsible for water percolation in the concretes. The percent water percolation for mortars in the presence of $\mathrm{SP}$ and $\mathrm{Na}_{2} \mathrm{SO}_{4}$ are shown in Figure 5. The presence of $\mathrm{FA}, \mathrm{SP}$ and $\mathrm{Na}_{2} \mathrm{SO}_{4}$ during hydration reduces the pore size, giving a dense structure. This is because of the formation of additional amount of C-S-H. Due to decrease in pore size and pore size distribution the water percolation decreases. From Figure 5, it is apparent that in the presence of FA and SP, the structure of hydration products is denser as compared to that in the presence of $\mathrm{Na}_{2} \mathrm{SO}_{4}$ or $\mathrm{Na}_{2} \mathrm{SO}_{4}+\mathrm{SP}$ and as a result the water percolation is decreased.

The air content in different moulds is shown in Figure 6. From the curve it is clear that the value is the minimum for FAOPC in the presence of $0.1 \mathrm{wt}$. (\%) SP. This again confirms that in the presence of SP the structure becomes denser and the pore size is reduced. In the

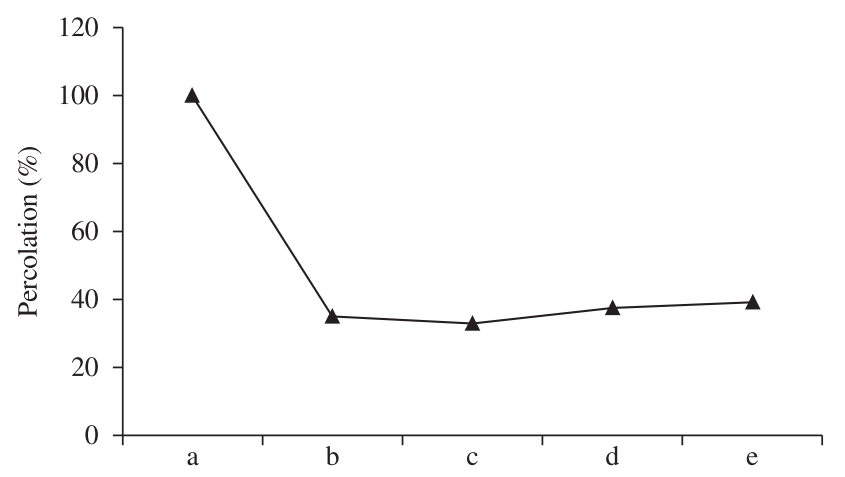
a) $\mathrm{OPC}$
b) $\mathrm{OPC}+20 \%$ fly ash
c) $\mathrm{OPC}+20 \%$ fly ash $+0.1 \% \mathrm{SP}$
d) $\mathrm{OPC}+20 \%$ fly ash $+2 \% \mathrm{Na}_{2} \mathrm{So}_{4}$
e) $\mathrm{OPC}+20 \%$ fly ash $+2 \% \mathrm{Na}_{2} \mathrm{So}_{4}+0.1 \% \mathrm{SP}$

Figure 5. Water percolation in different system.

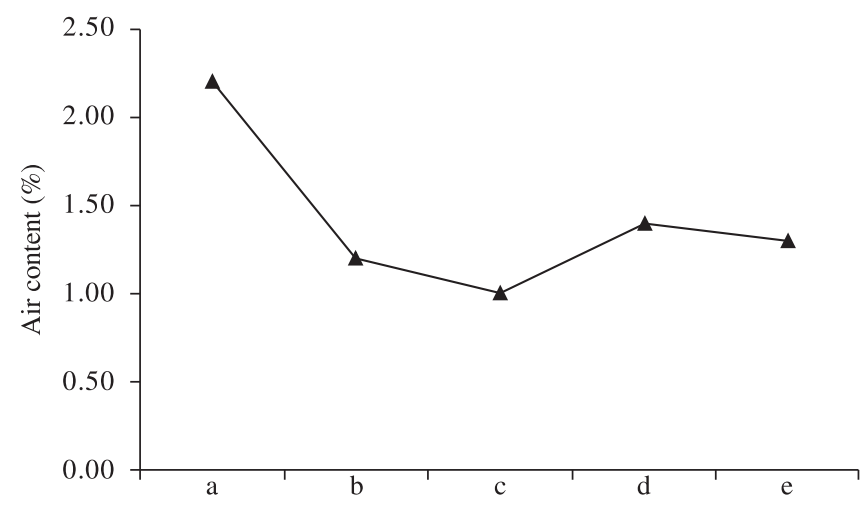
a) $\mathrm{OPC}$
b) $\mathrm{OPC}+20 \%$ fly ash
c) $\mathrm{OPC}+20 \%$ fly ash $+0.1 \% \mathrm{SP}$
d) $\mathrm{OPC}+20 \%$ fly ash $+2 \% \mathrm{Na}_{2} \mathrm{So}_{4}$
e) $\mathrm{OPC}+20 \%$ fly ash $+2 \% \mathrm{Na}_{2} \mathrm{So}_{4}+0.1 \% \mathrm{SP}$

Figure 6. Air content in different system. presence of $2.0 \mathrm{wt}$. (\%) $\mathrm{Na}_{2} \mathrm{SO}_{4}$ the hydration of FAOPC is accelerated and as a result more hydration products are formed but do not make the structure dense, so the air content in the mould is increased. However in the presence of a mixture of $\mathrm{SP}$ and $\mathrm{Na}_{2} \mathrm{SO}_{4}$, there is a resultant effect as obvious from the figure. This again confirms that in the presence of $\mathrm{Na}_{2} \mathrm{SO}_{4}$, the adsorption of $\mathrm{SP}$ is decreased and as a result its dispersing power is reduced. Because of this the structure is not as dense as in the presence of SP alone.

The compressive strengths of different mortars hydrated for 28 days are given in Figure 7. The results show that the compressive strengths of

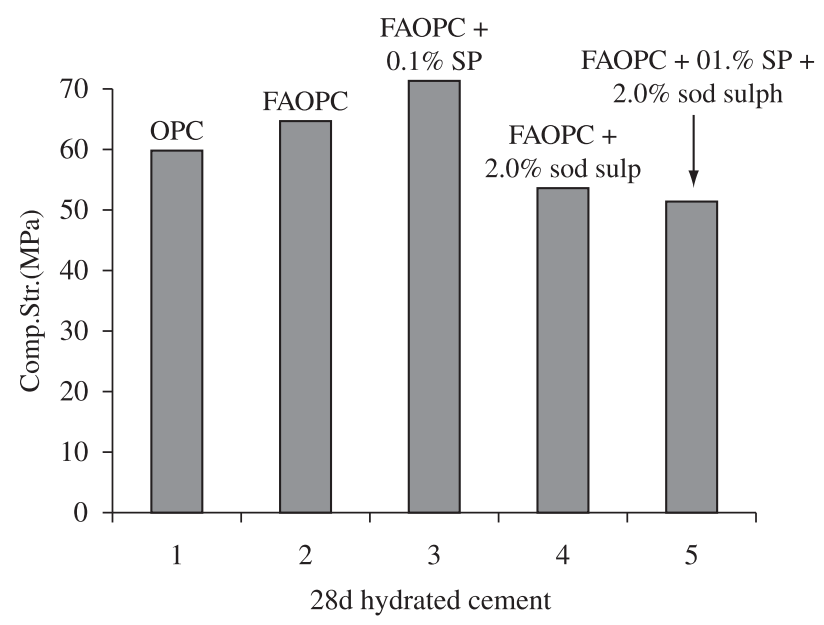

Figure 7. Compressive strength in different systems at 28 days of hydration.

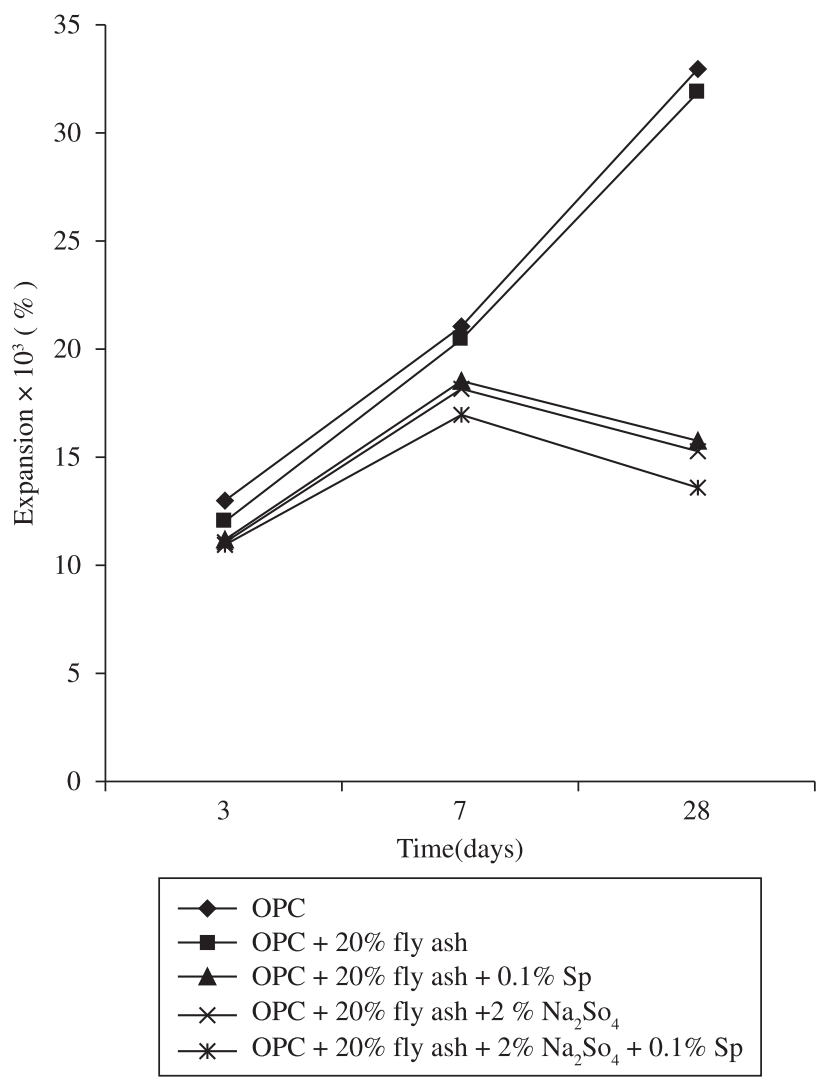

Figure 8. Variation of percent expansion with time in $\mathrm{N} / 60 \mathrm{H}_{2} \mathrm{SO}_{4}$. 
FAOPC in the presence of $0.1 \mathrm{wt} .(\%) \mathrm{SP}$ is maximum. By definition, the compressive strength of a material is that value of uniaxial compressive stress at which the material fails completely. The compressive strength of mortars depends on number of factors such as: degree of hydration, quality of cement, sand, w/c ratio, temperature, particle size distribution, the pore size, pore size distribution, etc. However pore size is one of the important factors controlling compressive strength. In general lower the porosity, higher the compressive strength. In the presence of $0.1 \mathrm{wt}$. (\%) SP the compressive strength is the maximum which clearly shows that pore size is decreased. Thus in the case of FAOPC, SP reduces the pore size or blocks the pores and as a result the compressive strengths are increased.

The effect of corrosive atmosphere on cement moulds in the presence of dilute $\mathrm{H}_{2} \mathrm{SO}_{4}$ was studied and the expansions were measured as a function of time (Figure 8). The expansion of the mould FAOPC in the presence of 0.1 wt. (\%) SP was much lower at all the times. The degradation mechanisms of cementitious materials are greatly influenced by the penetration ability of aggressive fluids, and there is an important relation between the pore structure of solids, fluid transport properties and degradation. This means that if the pore structure of the mortar is of different size than that of traditional concrete, some changes in durability behaviour might be expected. Since in the presence of SP the corrosive action of $\mathrm{H}_{2} \mathrm{SO}_{4}$ is decreased considerably, it shows that SP reduces the pore size of the FAOPC paste and does not allow the acid to enter in the pores.

TG and DTA studies of the hydrated samples (28 days) were also recorded (Figure 9). The shape of the curves was almost similar. The only differences were in the amount of hydration products in the

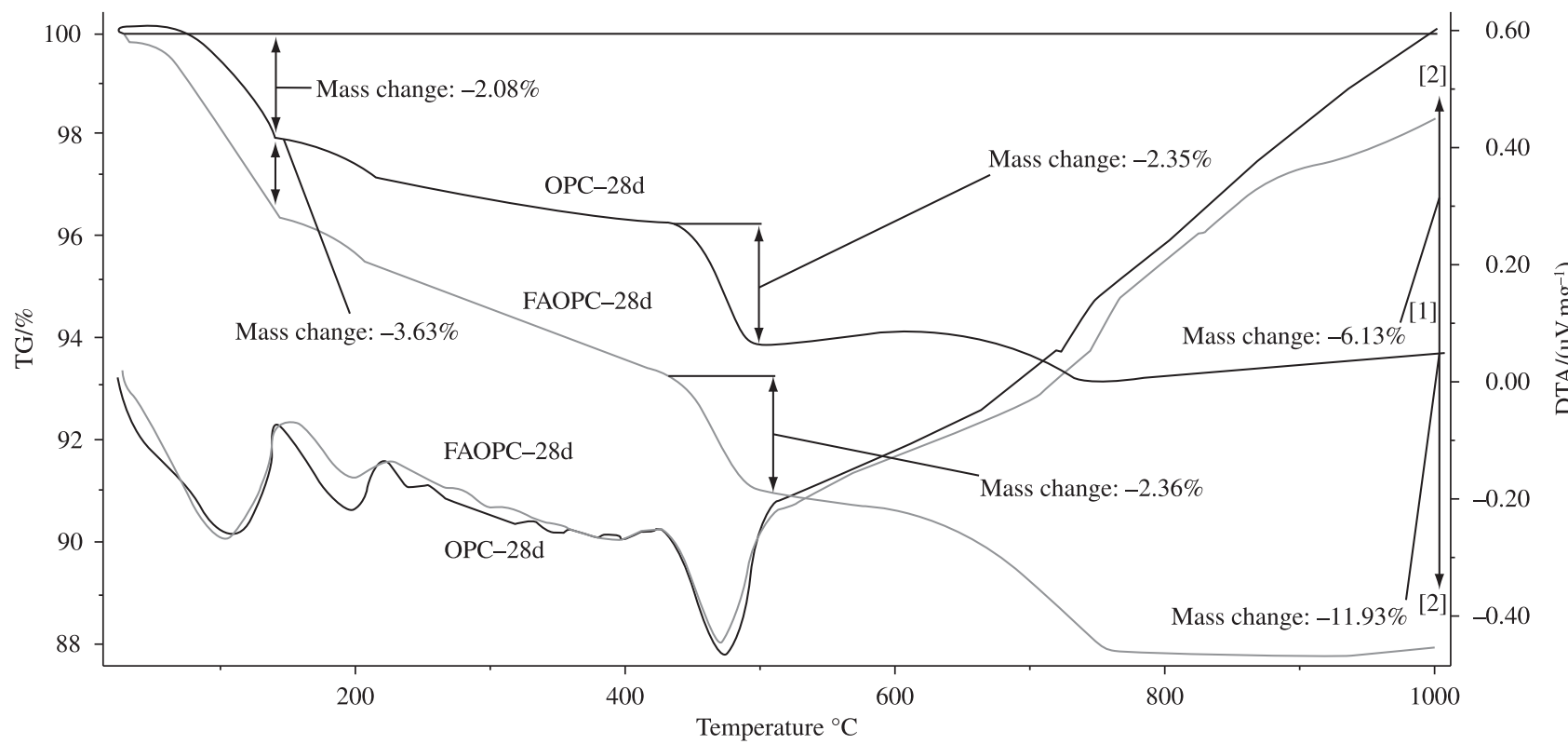

(a)

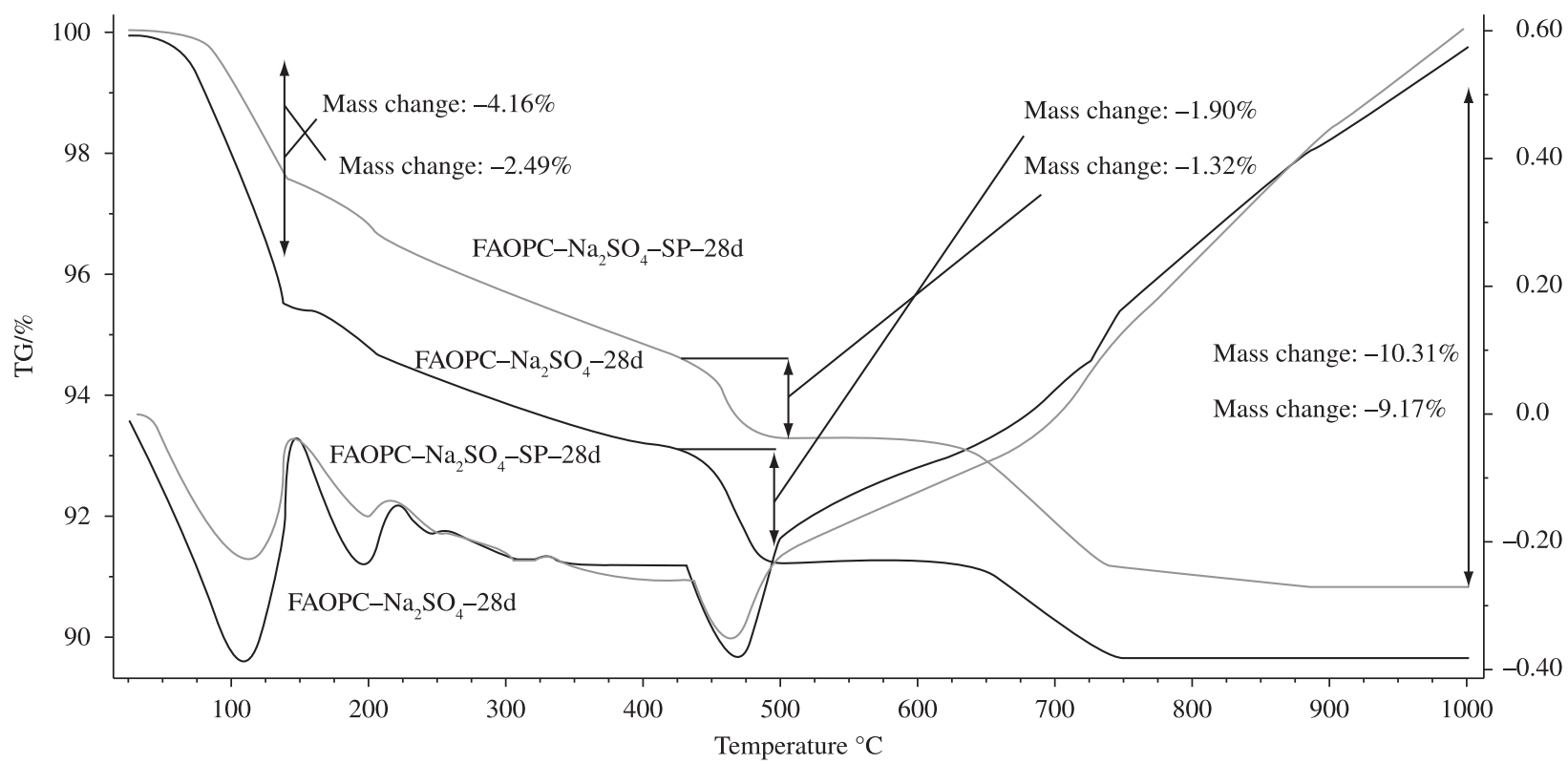

(b)

Figure 9. DTA curves of 28 days hydrated sample. 

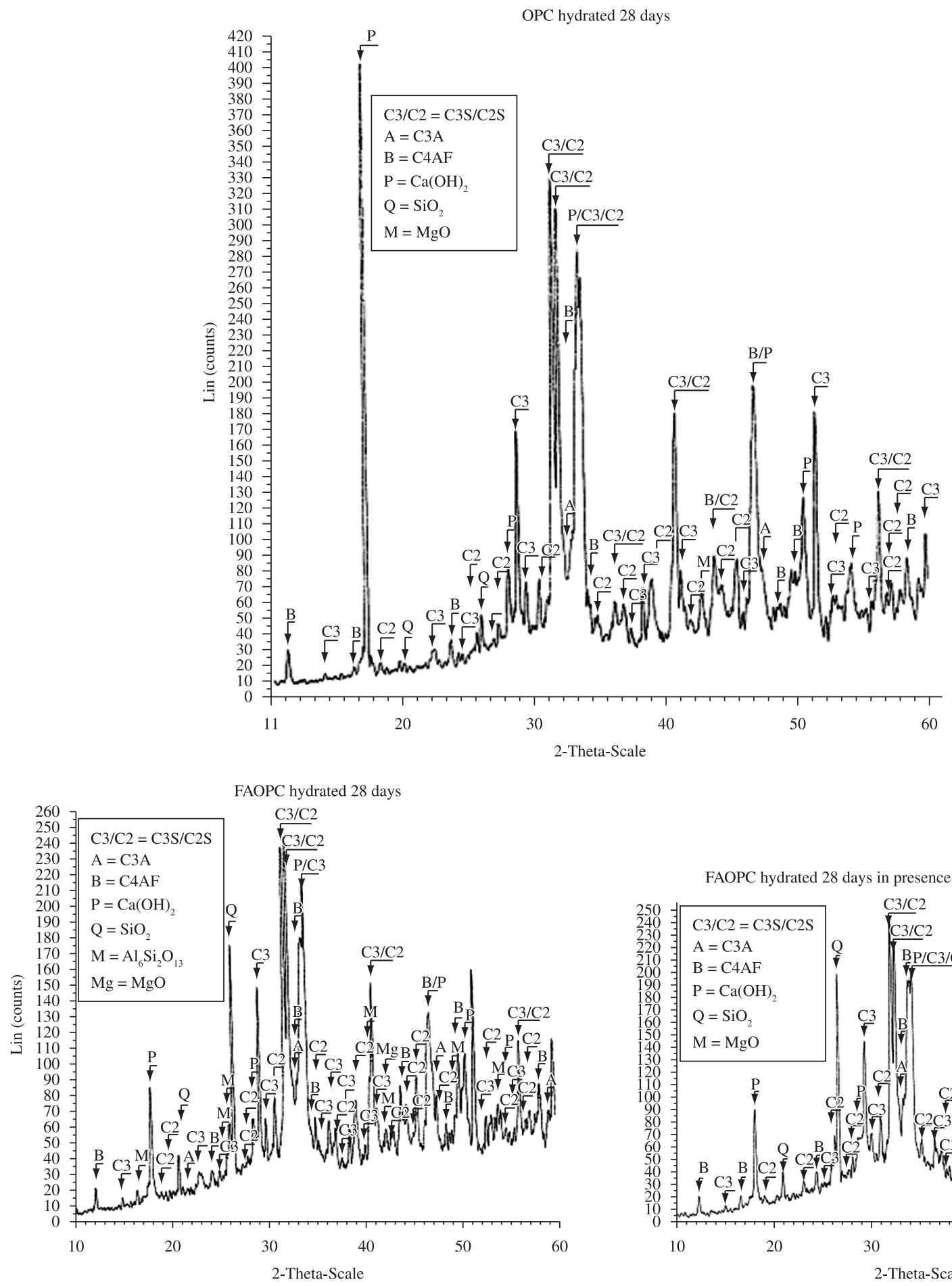

Figure 10. XRD patterns of 28 days hydrated sample.

hydrated samples. This is indicated by the differences in the peak areas (DTA peaks). In all the cases there are three endothermic peaks below $300{ }^{\circ} \mathrm{C}$. The peaks are due to removal of adsorbed water and decomposition of ettringite and $\mathrm{C}-\mathrm{S}-\mathrm{H}$ phase. The strong endothermic peak at about $450{ }^{\circ} \mathrm{C}$ is due to decomposition of calcium hydroxide formed during hydration. The peak area in the case of FAOPC hydrated for 28 days in the presence of $0.1 \mathrm{wt}$. (\%) superplasticizer and $2.0 \mathrm{wt}$. (\%) sodium sulphate is found to be minimum. This shows that the pozzolanic activity of fly ash is enhanced in the presence of 0.1 wt. (\%) superplasticizer and 2.0 wt. (\%) sodium sulphate. X-ray diffraction studies (Figure 10) also confirm the above finding. The amount of calcium hydroxide is the minimum in the presence of superplasticizer and sodium sulphate.

The overall results show that superplasticizer is adsorbed on the surface of FAOPC blended cement and modifies the structure of the hydrated matrix. However in the presence of sodium sulphate 
the adsorption of superplasticizer is decreased. In the presence of a mixture of superplasticizer and sodium sulphate there is a resultant effect on the compactness of the structure.

\section{Conclusions}

The results have shown that superplasticizer reduced the pore size of fly ash blended Portland ${ }^{\circledR}$ cement during hydration and decreased water percolation and increased 28 days compressive strength. Sodium sulphate accelerated the hydration and increased the activity of fly ash but in its presence the adsorption of superplasticizer is decreased. As a result the compactness of the structure of the hydrated matrix in the presence of sodium sulphate and superplasticizer is not as high as in the presence of superplasticizer alone.

\section{Acknowledgments}

One of us (Mukesh Kumar) is grateful to Mr. Ron Yuers , Chairman- KIM, Canada \& Mr. Umesh K. Kakkar, Managing Director, KBCPL, India for allowing to do this project and providing all the laboratory facilities.

\section{References}

1. Singh NB and Middendorf B. Chemistry of blended cements part-I: natural pozzolanas, fly ashes and granulated blast furnace slags. Cement International. 2008; 6(4):76-91.
2. Singh NB and Middendorf B. Chemistry of blended cements part-II: silica fume, metakaolin, reactive ashes from agricultural wastes, inert materials and non-Portland blended cements. Cement International. 2009; 7(6).

3. Lee CY, Lee HK and Lee KM. Strength and microstructural characteristics of chemically activated fly ash-cement systems. Cement and Concrete Research. 2003; 33(3):425-431.

4. Lorenzo MP, Goñi S and Guerrero A. Activation of pozzolanic reaction of hydrated portland cement fly ash pastes in sulfate solution. Journal of American Ceramic Society. 2004; 85(12):3071-3075.

5. Kumar R, Kumar S and Mehrotra SP. Towards sustainable solutions for fly ash through mechanical activation. Resources, Conservation and Recycling. 2007; 52(2):157-179.

6. Nawa T and Eguchi H. Effect of cement characteristics on the fluidity of cement paste containing an organic admixture. In: International Congress on Cement Chemistry; 1992; New Dehli, India. New Dehli. p. 579-603.

7. Chiocchio $\mathrm{G}$ and Paolini AE. Optimum time for adding superplasticizers to portland cement pastes. Cement and Concrete Research. 1985; 15(5):901-908.

8. Andersen PJ, Kumar A, Roy DM and Wolf-Confer D. The effect of calcium sulphate cencentration on the adsorption of a superplasticizer on a cement:methods, zeta potential and adsorption studies. Cement and Concrete Research. 1986; 16(2):255-259.

9. Kim BG, Jinag SP and Aitcin PC. Slump improvement mechanism of alkalies in PNS superplasticized cement paste. Materials and Structures. 2000; 33(225-234):363-369. 